\title{
ANálise Espaço-Temporal dos Roubos de Veículos Ocorridos Durante o ANo de 2013 nas Regióes das Áreas de Segurança Pública INTEGRADA 4 E 6 NO RIO DE JANEIRO
}

\author{
Wellington Clay Porcino Silva
}

Departamento de Polícia Federal - Brasil Universidade Nova de LisboA - ISEGI

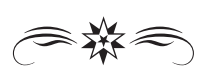

\section{RESUMO}

O presente trabalho procurará analisar as características espaciais e temporais dos roubos de veículos ocorridos nas regiões das áreas de segurança pública integradas (AISP) 4 (São Cristóvão e parte da Zona Portuária) e 6 (Região da Grande Tijuca) na cidade do Rio de Janeiro, de modo a determinar a frequência espacial e temporal de tais fatos, como forma de permitir aos gestores policiais um emprego mais eficiente de seus meios humanos e materiais.

Palavras-Chave: Análise Criminal. Roubos de Veículos. Rio de Janeiro. Polícia.

\section{INTRODUÇÃ̃o}

O presente trabalho analisará os dados referentes aos registros de roubos de veículos ocorridos em 2013 nas áreas de segurança integradas (AISP) 4 e 6, na cidade do Rio de Janeiro, correspondentes aos bairros de São Cristóvão e Caju (AISP 4) e da Grande Tijuca (AISP 6). Importante ressaltar que os dados utilizados no presente estudo foram obtidos junto ao Instituto de Segurança Pública da Secretaria de Segurança Pública do Estado do Rio de Janeiro, aproveitando a ocasião para externar os agradecimentos àquele órgão pela presteza no atendimento à solicitação dos dados aqui apresentados. 


\section{Objetivos}

Durante o desenvolvimento do presente trabalho, procurar-se-á realizar um estudo de Análise Criminal tendo como base os registros de roubos e veículos ocorridos no ano de 2013 nas AISP 4 e 6. Para tanto, os aspectos temporal e espacial dos dados em estudo serão analisados sob diversos ângulos, através do uso de ferramentas de estatística e de Sistemas de Informações Geográficas.

Buscar-se-á, na presente análise, não somente descrever os dados obtidos. O objetivo será, a partir da análise criteriosa de tais informações, identificar padrões que forneçam subsídios para auxiliar as forças policiais a melhor empregarem seus restritos meios.

Partindo da finalidade da inteligência policial, como descrita na Doutrina de Inteligência Policial da Polícia Federal, em seus aspectos de assessoramento e de subsídio à atividade fim, exemplificar-se-á como a análise criminal poderá auxiliar a força policial em qualquer de suas atividades típicas.

No caso concreto, os dados serão empregados para a criação de mapas temáticos e gráficos de frequência de modo que se permita a detecção de padrões. Tais resultados poderão ser de grande valia durante o planejamento do policiamento ostensivo na região estudada.

Ressalte-se que, com o desenvolvimento de novos modelos de negócios destinados a tornar a atividade policial mais eficiente, baseados fortemente nos trabalhos de inteligência e análise criminal, como o policiamento orientado ao problema e o policiamento orientado pela inteligência, mais necessário se faz o desenvolvimento de técnicas que otimizem tais trabalhos já que o tempo é sempre uma questão crítica nos meios policiais.

Dessa forma, com o presente trabalho, buscar-se-á contribuir para o desenvolvimento da cultura de planejamento e de inteligência nos órgãos policiais em substituição aos modelos baseados no empirismo que tradicionalmente orientam o processo decisório policial. 


\section{3. Área Objeto de Estudo}

Segue abaixo figura indicando a área objeto de estudo no presente artigo.

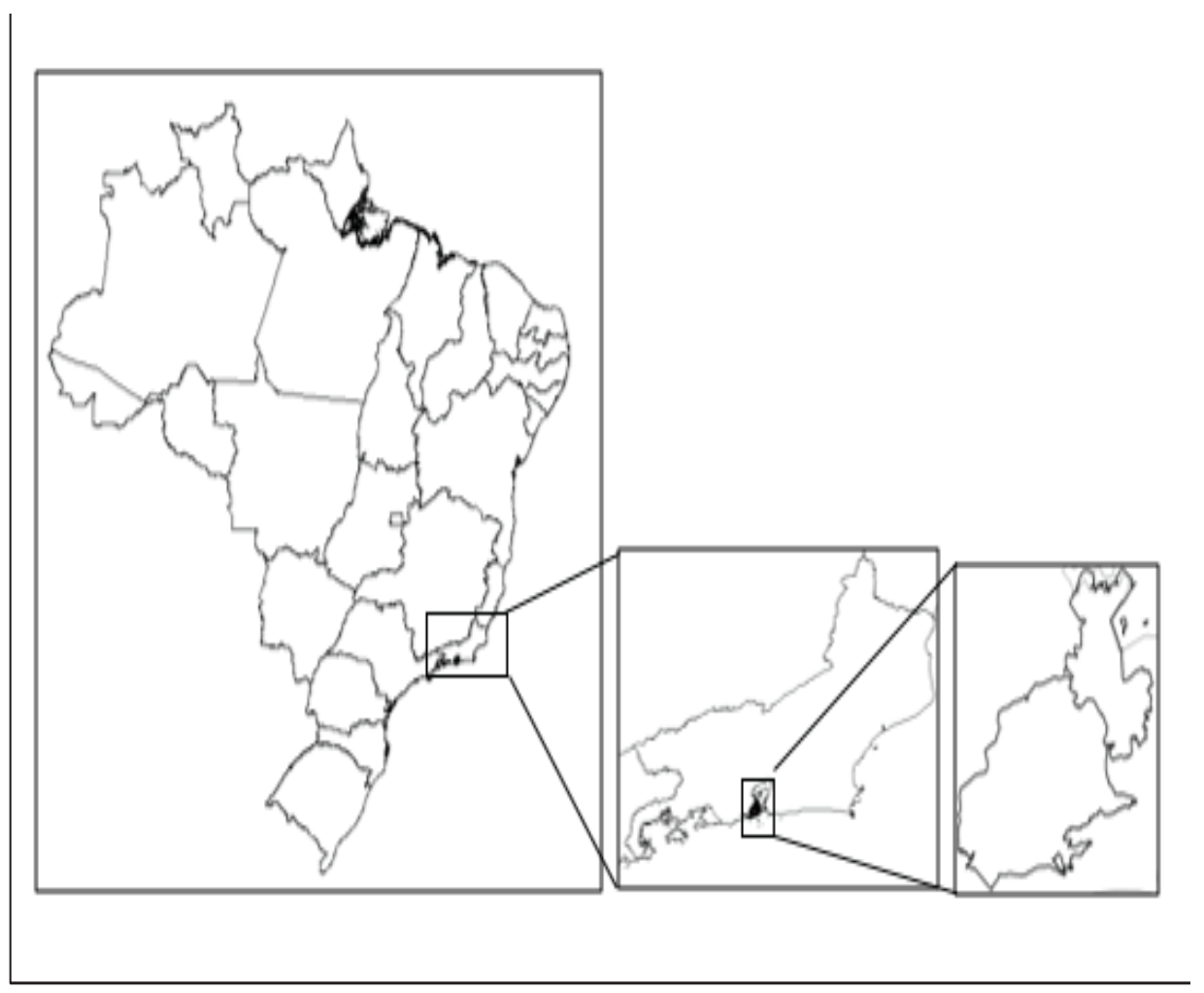

Figura 1 - Área objeto de estudo

\section{Dados Analisados}

Os dados analisados foram fornecidos pelo Instituto de Segurança Pública (ISP) da Secretaria de Segurança Pública do Estado do Rio de Janeiro, mediante solicitação, a fim de que se pudesse produzir o presente trabalho, como forma de contribuição ao debate referente à Segurança Pública na busca incessante de órgãos policiais cada vez mais eficientes.

No caso concreto foram fornecidos três arquivos, como descrito no quadro abaixo: 


\begin{tabular}{|c|c|c|}
\hline Nome & Tipo & \multicolumn{1}{|c|}{ Descrição } \\
\hline AISP04_06 & Shapefile & $\begin{array}{l}\text { Shapefile com os polígonos corres- } \\
\text { pondentes às AISP 4 e 6. }\end{array}$ \\
\hline Dados_RV & Shapefile & $\begin{array}{l}\text { Shapefile do tipo ponto com os lo- } \\
\text { cais de ocorrências de roubo de veí- } \\
\text { culos nas AISP 4 e 6 no ano de 2013. }\end{array}$ \\
\hline Microdados_RV_aisp4e6 & Planilha & $\begin{array}{l}\text { Planilha com os dados referentes aos } \\
\text { eventos de roubo de veículos ocorri- } \\
\text { dos nas AISP 4 e 6 no ano de 2013. }\end{array}$ \\
\hline Dicionário de Variáveis & Apresentação & $\begin{array}{l}\text { Apresentação com o dicionário de } \\
\text { variáveis utilizados nos dados ante- } \\
\text { riormente citados. }\end{array}$ \\
\hline
\end{tabular}

Tabela 1 - Dados Utilizados

A forma apresentada pelos dados acima referidos facilitou o trabalho já que, dada a qualidade apresentada, o pré-processamento desses - etapa que em projetos similares costumam exigir muito tempo - limitou-se ao estabelecimento de um sistema de referência geográfica para os arquivos do tipo shapefile, já que esse não foi previamente estabelecido, bem como pela exclusão de sete (7) registros que continham informações omissas no total de 588. Optou-se pela exclusão de tais registros do universo de estudo dado a sua pouca significância numérica.

Em relação ao Sistema de Referência Geográfica, com o emprego de ferramenta específica existente no Sistema de Informação Geográfica (SIG) utilizado, o Arc GIS 10.2, atribui-se o sistema de coordenadas geográficas com datum WGS 84, vez que esse é o mais empregado nos sistemas de posicionamento global (GPS), bem como por ser equivalente, para aplicações práticas, ao datum oficial brasileiro, o SIRGAS 2000.

Segue abaixo, mapa representando a localização dos roubos de veículos ocorridos ao longo do ano de 2013 nas AISP 4 e 6, bem como os limites das mencionadas AISP. 

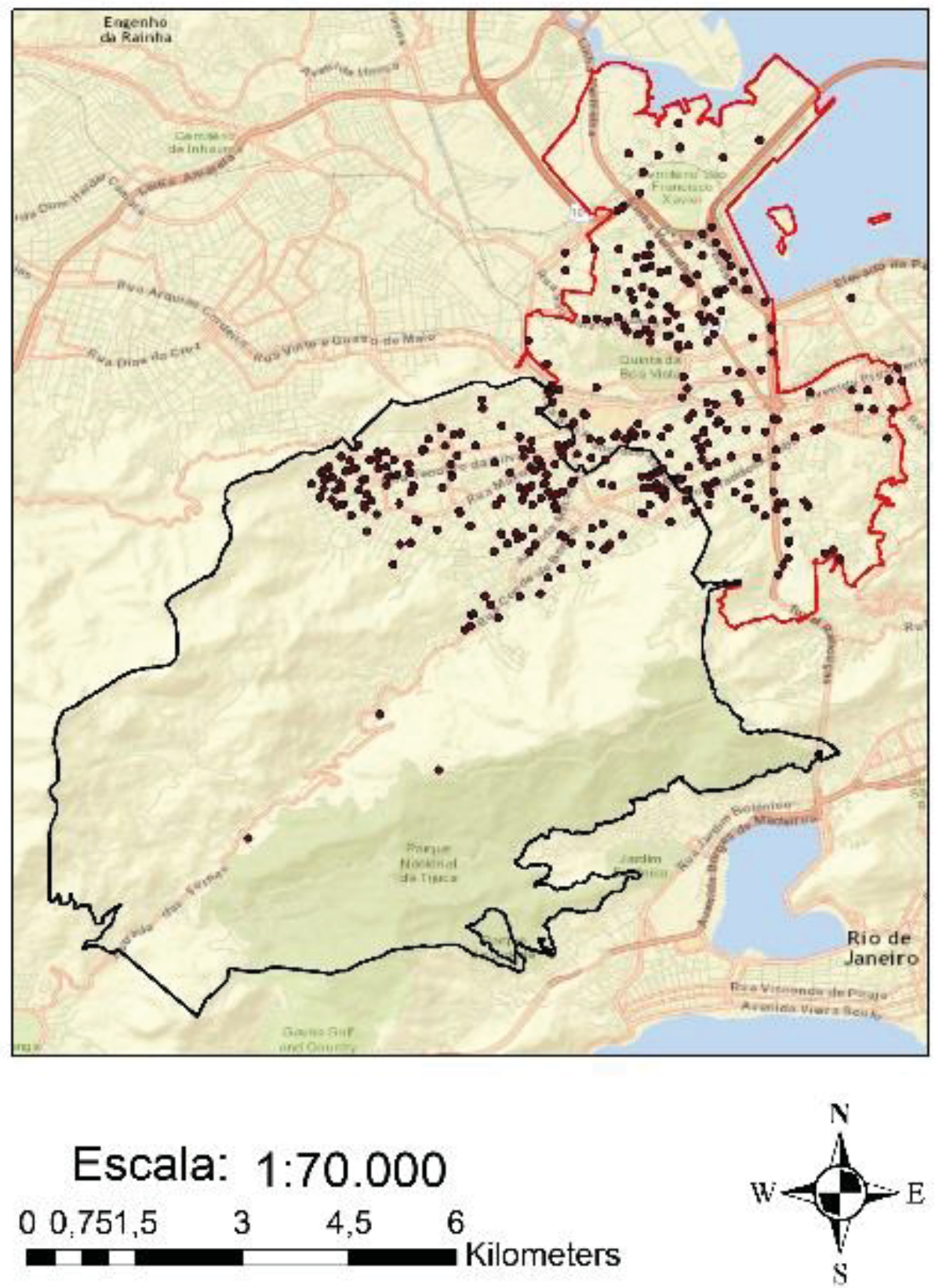

Fonte dos Dados:ISP/SSP-RJ

Figura 2 - Roubos de Veículos AISP 4 e 6 - Ano de 2013

\section{ANÁlise EsPaÇo-Temporal}

A seguir, apresentar-se-á o resultado do trabalho de análise dos dados referentes aos eventos criminosos sob exame. Como já se mencionou, estudar-se-ão os delitos de roubos de veículos ocorridos no ano de 2013 nas AISP 4 e 6 da Cidade do Rio de Janeiro. 
Decidiu-se por analisar esse crime em particular em razão de dois fatores principais: o primeiro se relaciona ao impacto que tal infração penal tem na sensação de segurança, já que a violência associada a este delito, aliado ao alto valor do bem subtraído, geram considerável insegurança em todos aqueles cidadãos atingidos direta ou indiretamente. Ademais, crimes patrimoniais contra veículos tem altíssima taxa de notificação, isto é, apresentam cifra negra extremamente pequena, talvez pela necessidade de registro de ocorrência para recebimento do valor do seguro do bem subtraído. Estudos realizados no EUA, na Inglaterra e na Holanda demonstram que a taxa de notificação de tal tipo de crime varia entre 93\% e 97\% (RATCLIFFE, 2011).

\section{I. ANÁlISE DA DISTRIBUIÇÃO TEMPORAL DOS EVENTOS CRI- MINOSOS}

Para o cálculo dos descritores estatísticos dos dados foi utilizada a função de estatística descritiva do Software EXCEL, obtendo-se como resultado a tabela a seguir.

\begin{tabular}{|c|c|c|c|}
\hline & HORA & DIA & M̂̂E \\
\hline Média & 15,8 & 4,22 & 6,8 \\
\hline Moda & 20 & 5 & 8 \\
\hline Contagem & 581 & 581 & 581 \\
\hline Curtose & 0,098968 & $-1,12087$ & $-1,15425$ \\
\hline
\end{tabular}

Tabela 2 - Descritores estatísticos dos dados analisados

Dos valores acima, destaca-se, dentre as medidas de localização central, como de relevância para o estudo que se pretende, a análise da Moda, que representa, em um determinado conjunto de dados, o valor que ocorre o maior número de vezes naquela dada amostra.

Verifica-se que, assim, a hora na qual mais roubos ocorreram foi às 20:00 horas, bem como o dia da semana com mais incidência de eventos é a quinta feira, enquanto o mês com maior número de ocorrência foi o mês de agosto.

Contudo, para uma correta interpretação dos dados estatísticos, faz-se necessária a análise das medidas de dispersão, isto é, aquelas que indicam a forma pela qual os dados estão dispersos em uma determinada amostra. Den- 
tre essas, o presente estudo abordará a denominada curtose, que caracteriza o pico ou achatamento da função de distribuição de um determinado conjunto de dados (CASSELA et al., 2010). Será igual a 3 (três) no caso de distribuição normal. No caso concreto, todos os valores são menores que três o que indica uma distribuição não normal.

Ressalte-se que, no caso de eventos criminosos, tal forma de distribuição é esperada, já que delitos têm uma tendência de concentrarem-se em determinados locais e horários, seja em função do número de vítimas disponíveis, ou do menor policiamento em determinados momentos (troca de plantões, por exemplo) ou ainda por causa das condições do ambiente.

Tendo em vista o acima exposto, é conveniente que, para se analisar adequadamente a forma pela qual os roubos de veículos se distribuem no tempo, dentro do nosso espaço amostral, construam-se gráficos de frequência, ou histogramas.

Tais gráficos permitem verificar como se dá, dentro da amostra analisada, a distribuição dos valores assumidos pela variável, o que permitirá uma visão mais detalhada da forma pela qual os eventos se concentram no tempo.

O gráfico abaixo representa a distribuição dos roubos analisados em relação ao horário de ocorrência.

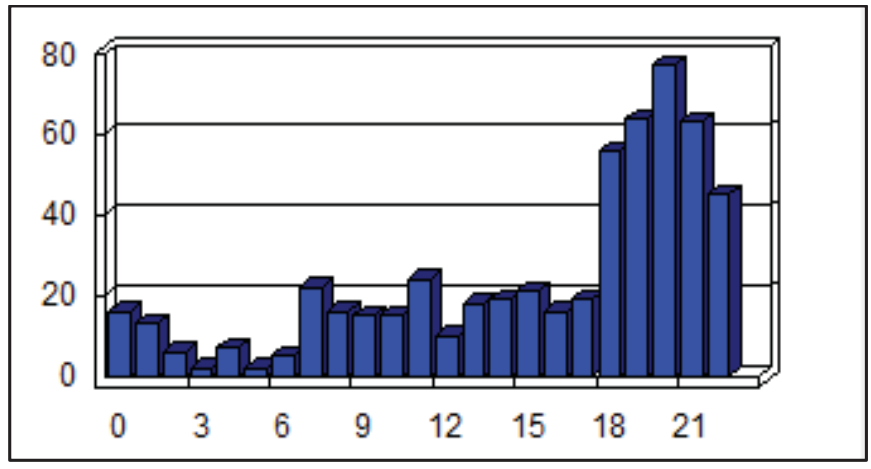

Figura 3 - Gráfico de distribuição roubo de Veículos por hora

Da simples visualização do gráfico acima, podemos identificar que a maior parte dos delitos ocorrem, como era de se esperar, no período noturno, após as 18 horas. Contudo, é perceptível que há uma grande concentração de tais eventos na parte inicial da noite, entre 18 e 22 horas, reduzindo-se sua frequência drasticamente após a meia-noite. Ressalte-se que, como já mencionado, um dos principais objetivos da análise criminal é a identificação de padrões recorrentes em eventos criminosos de modo a permitir que a polícia 
empregue de forma mais eficiente seus meios, que sempre são escassos quando comparados com as necessidades.

Assim, tendo em vista o largo período de estudo utilizado (um ano), bem como a grande concentração de eventos em uma pequena parte do dia, isto é, em um período de 4 horas, parece relevante que o dado acima, ainda que não determinante, já que várias outras questões se impõem quando do planejamento tático e/ou estratégico de uma força policial, deva ser levado em consideração como um padrão relevante.

Ressalte-se, ainda, que o pequeno número de eventos durante a segunda parte da noite chega a contrariar o senso comum que costuma identificá-la como um período de alto risco, ideia não comprovada pela análise acima.

Abaixo, o gráfico de frequência referente aos dias de semana. Em relação aos dias de semana, percebe-se que há uma grande variação nos números de ocorrências no decorrer da semana, sendo que nos dias com maior quantidade de eventos, isto é, terças, quintas e sextas feiras, percebese que, em relação ao dia de menor incidência, qual seja, domingo, há uma redução próxima a metade no número de delitos, sendo que, nos outros dias a frequência, embora um pouco superior, permanece mais próxima desse patamar que nos dias de maior ocorrência.

Mais uma vez identifica-se um padrão que parece relevante para o processo decisório do policiamento na região estudada.

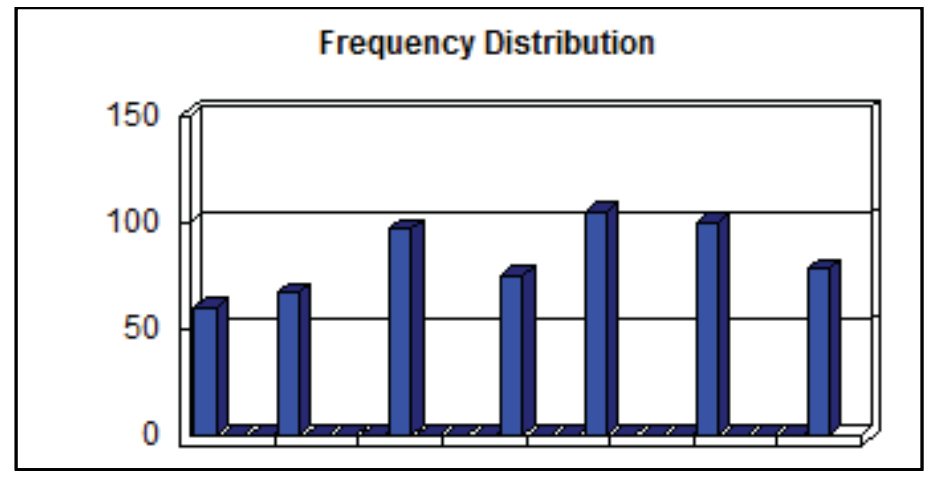

Figura 4 - Gráfico de distribuição Roubo de veículos por dia da semana - Domingo a segunda

Abaixo, verifica-se o histograma da distribuição das ocorrências por mês. Em relação à distribuição mensal dos roubos de veículos, percebe-se uma menor variação entre os três meses de maior incidência em relação aos 
outros, possuindo portanto uma distribuição mais uniforme, porém com picos nos meses de maio, agosto e dezembro.

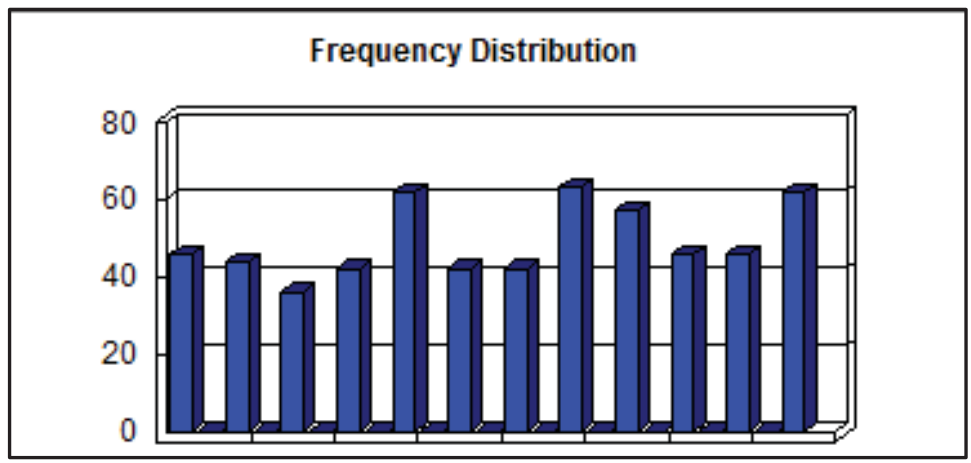

Figura 5 - Gráfico de distribuição roubo de veículos por mês - Janeiro a dezembro

Mais uma vez identifica-se um padrão que parece relevante para o processo decisório do policiamento na região estudada.

\subsection{ANÁLISE ESPACIAL}

O fenômeno crime está intimamente relacionado ao espaço. É impossível dissociar determinado delito do seu local de ocorrência, já que as características desse são determinantes para a sua consecução uma vez que para que seja cometida uma infração penal é necessário que estejam presentes no mesmo ponto vítimas viáveis, delinquentes potenciais, além da carência de elementos de segurança. Sem a conjunção desses fatores em determinada região, não ocorrerá o crime.

Como mencionado por Dantas e Ferro (2008), a aplicação da análise espacial permite a antevisão da repetição futura de determinado evento, o que permite, de forma científica e hoje já validada, uma previsibilidade. Nesse mesmo sentido Xue e Brown (2003).

Neste estudo, primeiramente, desenvolver-se-á uma análise de hot spots, isto é, a identificação de que contém uma quantidade não usual dos crimes sob análise. Tal modelo é empregado para identificar clusters de incidentes criminais em determinada região (ibidem).

Para a construção de tais hot spots, produzir-se-á mapas de superfície, também conhecidos como mapas de densidade de Kernel para os eventos 
criminosos estudados. Tais mapas dividem a área de estudo em diversas quadrículas e calculam o valor de cada uma com base no número e na proximidade dos locais de eventos criminosos (RATCLIFFE, 2004).

Outra técnica a ser demonstrada será a construção de elipses de cobertura ou de desvio padrão, construída de modo a cobrir um determinado cluster ocorrências. Tal técnica é muito popular, já que seu cálculo matemático é simples (SMITH et al., 2008).

Dessa forma, com a identificação dos padrões espaciais, bem como com os padrões temporais já explicitados, buscar-se-á fornecer subsídios ao planejamento e emprego das atividades de policiamento na área, a qual, sem dúvida alguma, poderá ser otimizada.

\subsubsection{ConstruÇão de hot SPOTS}

Como já mencionado, o primeiro passo na presente análise espacial será a identificação de hot spots. Para tanto, serão demonstradas duas técnicas: primeiramente através de elipses de cobertura e, posteriormente, através da construção de mapas de densidade. Contudo, antes, devido à relevância desse dado em matéria de policiamento ostensivo, buscar-se-á identificar o ponto central médio das ocorrências analisadas, isto é, o ponto médio central dos eventos estudados (SMITH et al., 2008), bem como a variação mensal desse descritor. Buscar-se-á, desta feita, verificar se há grande variação espacial mês a mês em relação a dispersão dos eventos criminosos estudados, de modo a validar a utilização dos dados de meses anteriores para a identificação dos locais onde há mais risco de ocorrer, futuramente, eventos como os estudados.

Segue abaixo figura contendo o centro médio de todos os eventos estudados no ano de 2013, bem como o calculado com os eventos mensais no período de janeiro a junho do referido ano. 


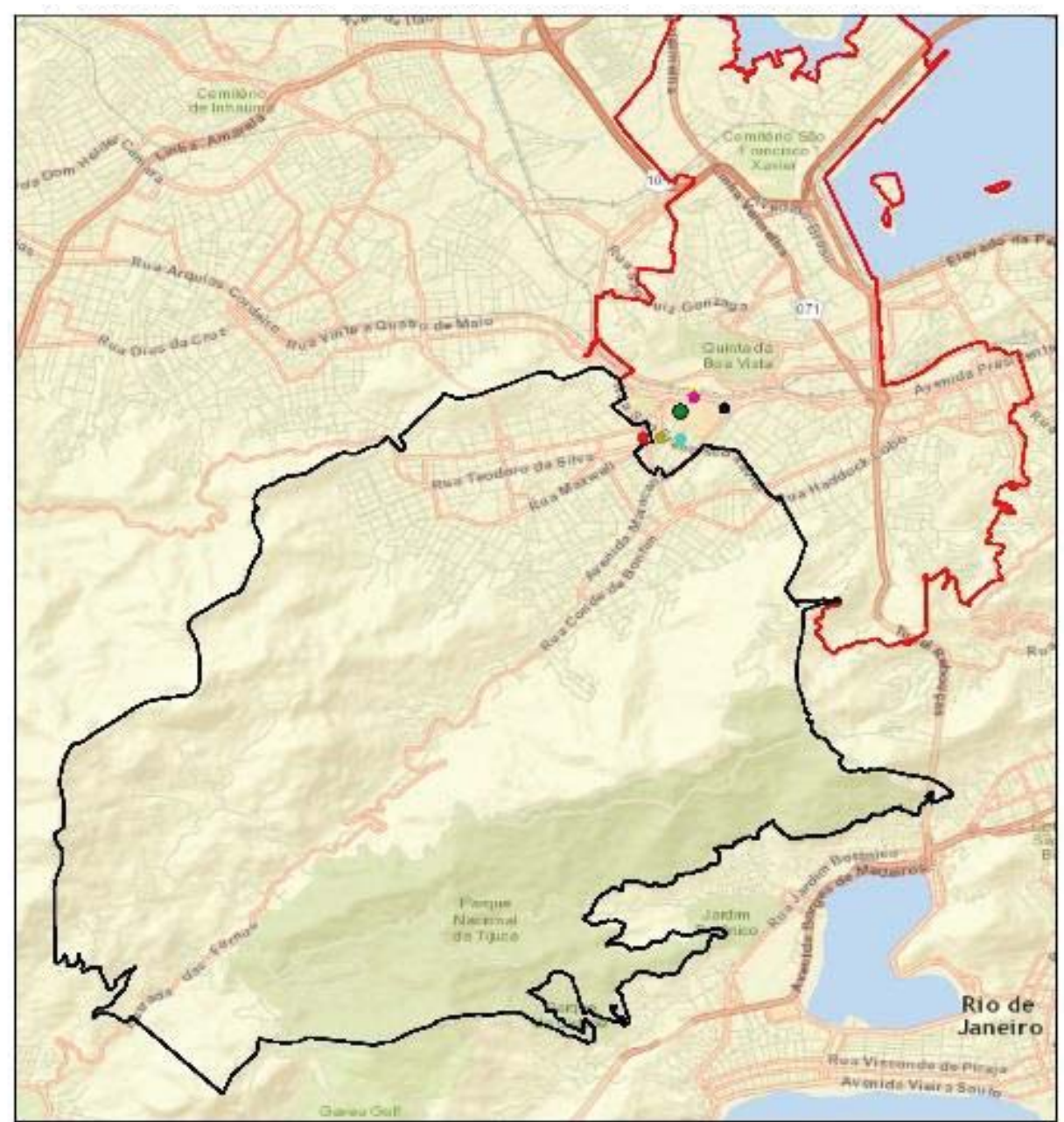

\section{Legenda}

a centa kcodoridu.

- Centa Nado Ristial

- Lente Xado Rovatr

Contes Stedo Rilial

- Contustedorituy

- Cantos kadio FV Jan

- Cantr mario FU z013

Grande Tjuca e Sao Cristovao AISP

Dao Cistares

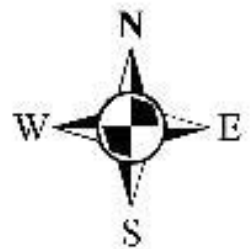

Estalet: $1: 70.000$ Fonte dos Dados:ISPISSP-RJ

Figura 6 - Centros Médio de Roubos de Veículos no ano de 2013 e nos meses de janeiro a julho

Assim, da simples leitura do mapa acima, verifica-se que, no caso dos dados analisados, a distribuição é extremamente concentrada na região fronteiriça das duas AISP estudadas. Outro ponto importante a ser avaliado é que a concentração mencionada permanece, independente do mês estudado, já que os centros médios dos eventos, mesmo quando analisados mês a mês permanecem concentrados em uma pequena parcela da área de estudo. 


\subsubsection{CONSTRUÇÃO DE ELIPSE DE DESVIO PADRÃO}

Ainda abordando a distribuição espacial dos eventos, buscar-se-á construir, agora, a elipse do desvio padrão. Esta figura tem como característica abranger 68\% (sessenta e oito por cento) dos eventos estudados. Se utilizássemos uma elipse de dois desvios padrões esta abrangeria 95\% (noventa e cinco por cento) dos incidentes. Em razão dessa característica, tais elipses são muito utilizadas para identificar regiões com grande incidência criminal. Tal elipse permite analisar as seguintes características espaciais dos eventos estudados: tendência central, dispersão e a orientação geral.

Segue abaixo a figura contendo as mencionadas elipses, sendo que estas foram construídas em relação aos crimes cometidos no ano de 2013 como um todo e mês a mês, durante o primeiro semestre.

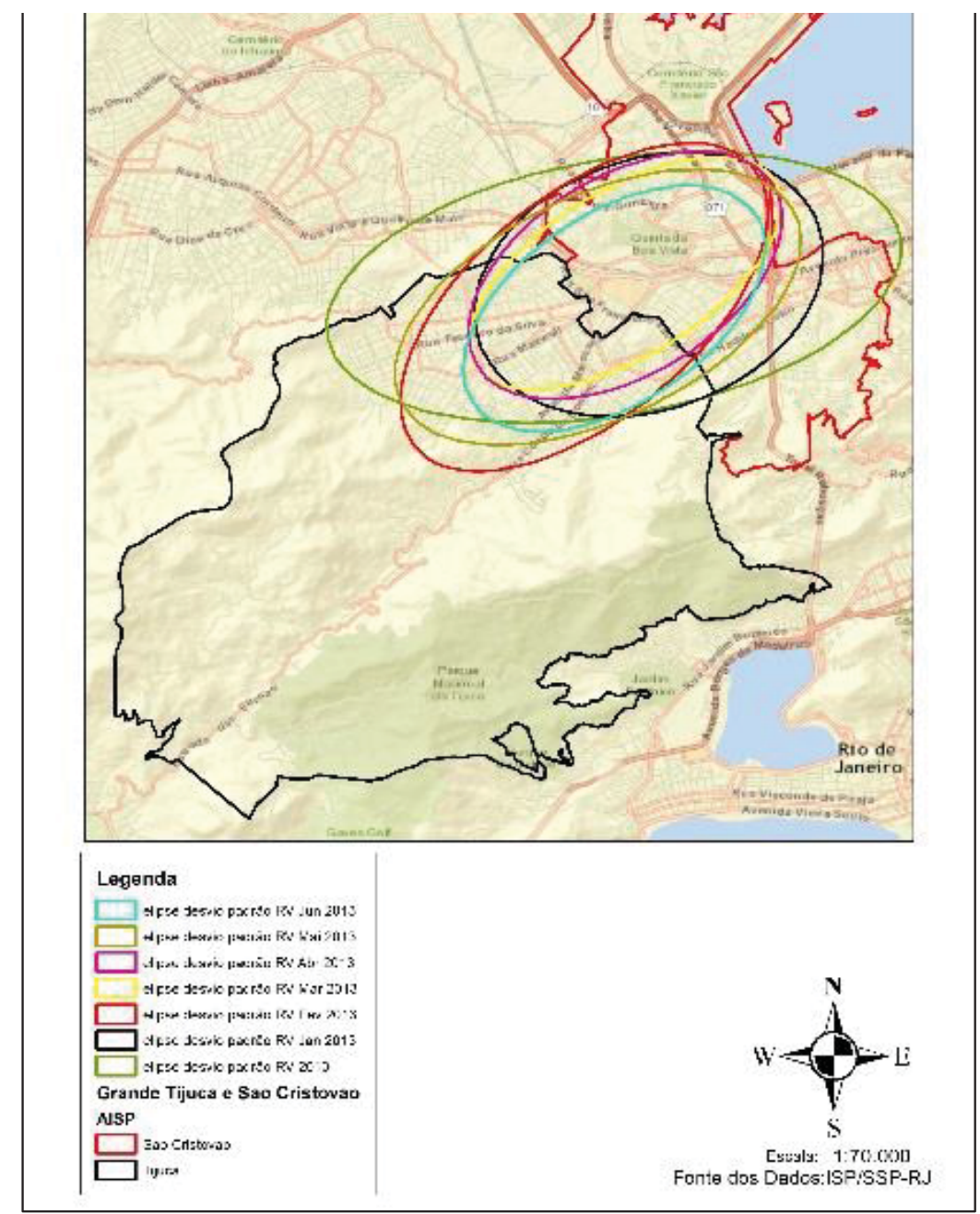

Figura 7 - Elipses de desvio padrão de Roubos de Veículos no ano de 2013 e nos meses de janeiro a julho 
Como se verifica na figura acima, todos os descritores de distribuição dos roubos de veículos sob análise, quais sejam, tendência central, dispersão e orientação geral não variam de forma significativa, independente do mês que se analise. Há, apenas, quando se compara a elipse gerada com todos os roubos de veículos ocorridos em 2013 com as feitas a partir dos dados mensais, uma pequena alteração na orientação geral, mas mesmo assim muito pouco relevante.

Isso reforça a hipótese de que os dados de roubos de veículos anteriores são relevantes para a identificação dos locais de maior risco de ocorrência de novos eventos criminosos.

Novamente, os dados analisados apontam para uma grande concentração espacial dos eventos, na região da AISP 4 próxima à divisa entre esta e a AISP 6.

Ainda como forma de demonstrar matematicamente a concentração dos roubos estudados, realizou-se uma análise do vizinho mais próximo para todos os dados do universo (ano de 2013), calculando-se o denominado z-score. Assim, para o valor obtido de $-25,77$ existe menos de $1 \%$ de chance de essa distribuição ser aleatória, demonstrando a grande concentração dos eventos analisados. Ressalte-se que um valor de z-score menor que -2,58 já seria suficiente para enquadrar os presentes dados nessa categoria.

Tratando agora do mapa de superfície a ser construído, pode-se afirmar que, em razão da já mencionada concentração de eventos, a utilização dos locais de roubos de veículos anteriores é um excelente parâmetro para o cálculo do risco de ocorrência futura deste tipo de eventos em determinado ponto.

Desta feita, pode-se considerar que os mapas de superfície a serem produzidos indicarão com boa confiabilidade a probabilidade futura de ocorrência.

No primeiro mapa produzido com a utilização da função Kernel do ArcGIS 10.2, representaram-se todos os eventos ocorridos no ano de 2013. Obteve-se, então, o produto que segue: 


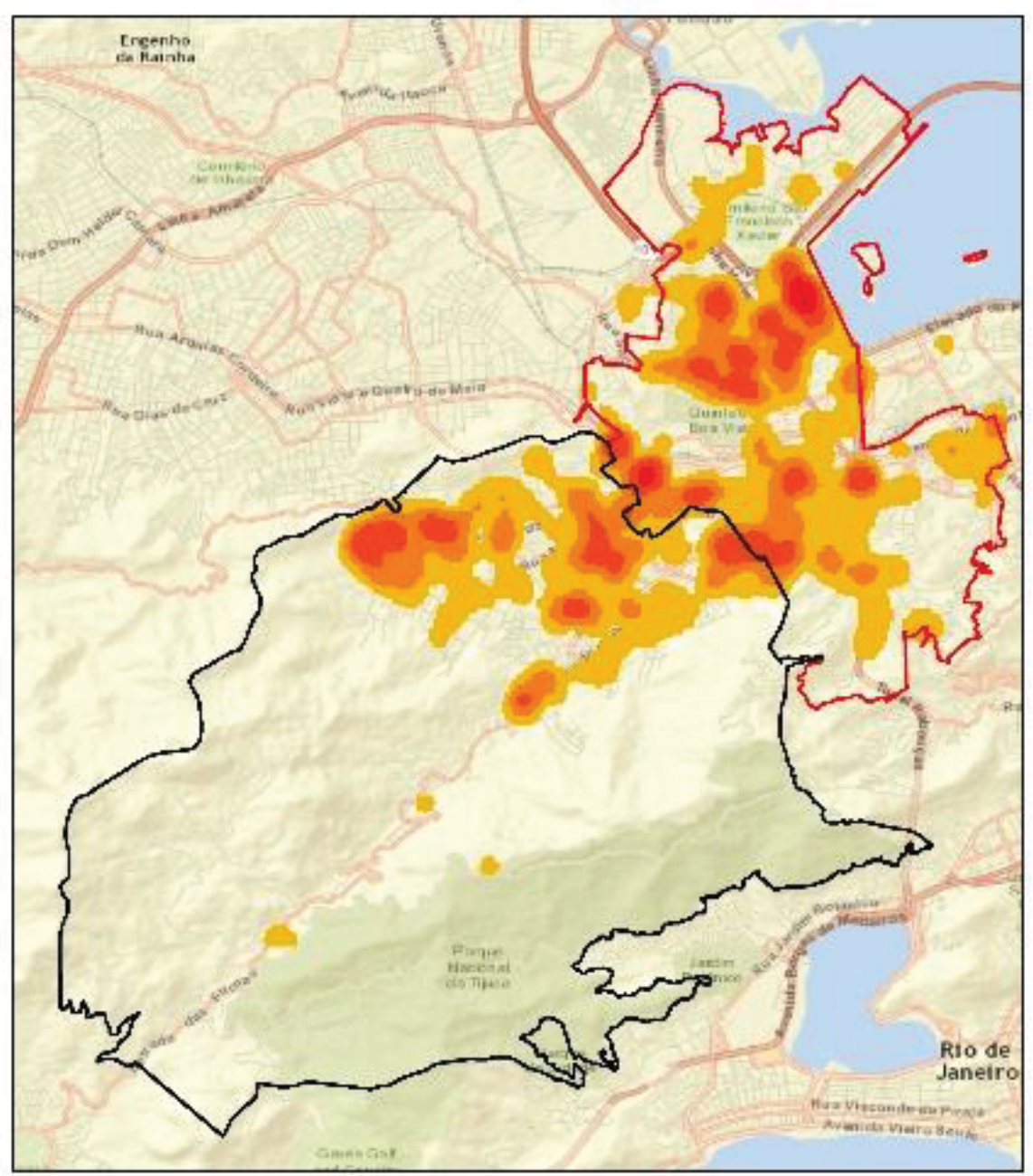

Escala: $1: 70.000$
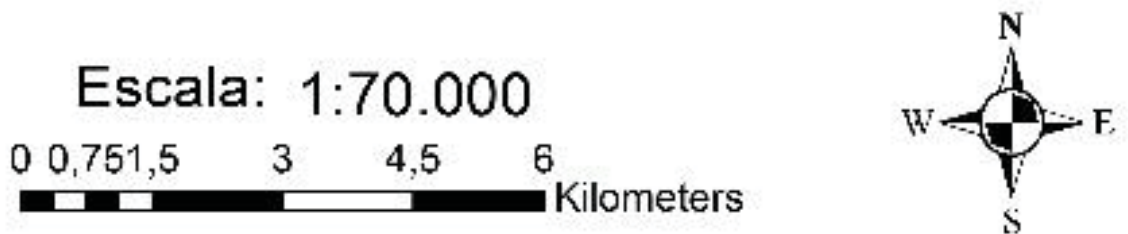

Fonte dos Dados:ISP/SSP-RJ

Figura 8 - Mapa de risco - Roubo de Veículos dados de 2013

Ao analisar-se o mapa acima, percebe-se que há áreas de grande risco próximas aos limites entre as AISP. Percebe-se também que os eventos na AISP 4 estão um pouco mais distribuídos do que em relação à AISP 6, com forte concentração mais ao norte da circunscrição, região essa realmente com alto índice de crimes, já que representa a confluência da Linha Vermelha com a Avenida Brasil, duas vias expressas das mais importantes da cidade, bem como pela proximidade com os complexos da Maré e do Caju. 
Contudo, tendo em vista que os dados utilizados na construção do mapa acima se referem a um longo período, isto é todo o ano de 2013, bem como para que não haja grandes variações mensais entre os principais hot spots, como já demonstrado acima, é conveniente, para um melhor planejamento tático, que sejam levados em consideração dados de um período mais curto. Assim, para verificar a eficiência da utilização de dados mensais para planejar o emprego da força policial no mês seguinte, passar-se-á a produzir mapas de risco com os dados referentes a cada um dos meses do primeiro semestre de 2013. Caso se verifique que a maior proximidade no tempo torna a avaliação de risco mais adequada, sugerir-se-á a utilização da análise mensal como subsídio para o planejamento tático das unidades policiais envolvidas, enquanto a análise dos dados anuais seria mais adequada para subsidiar ações de caráter estratégico e, portanto, de mais longo prazo.

Seguem abaixo os mapas referentes aos meses de janeiro a junho de 2013.

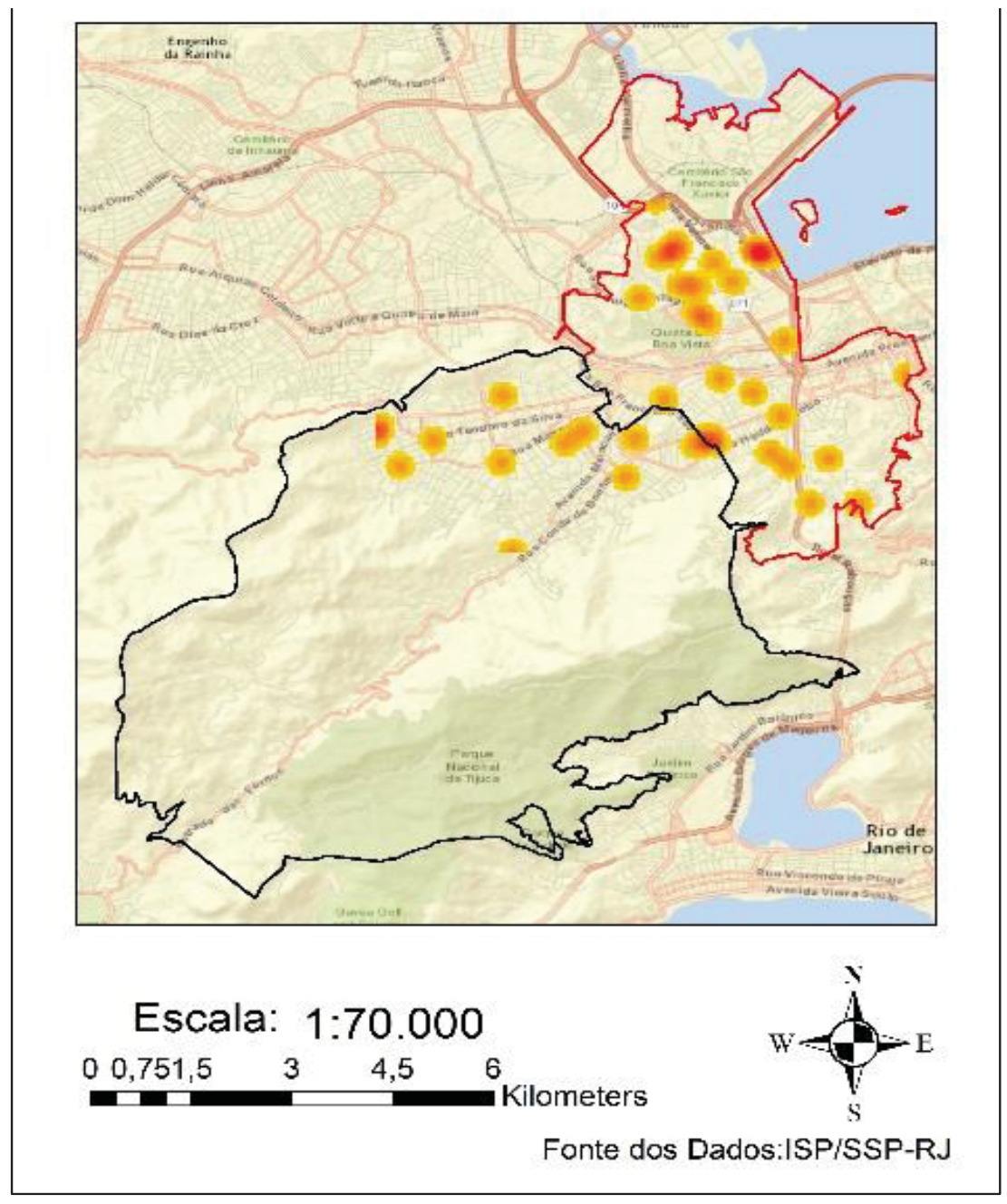

Figura 9 - Mapa de risco - Roubo de Veículos dados de janeiro de 2013 


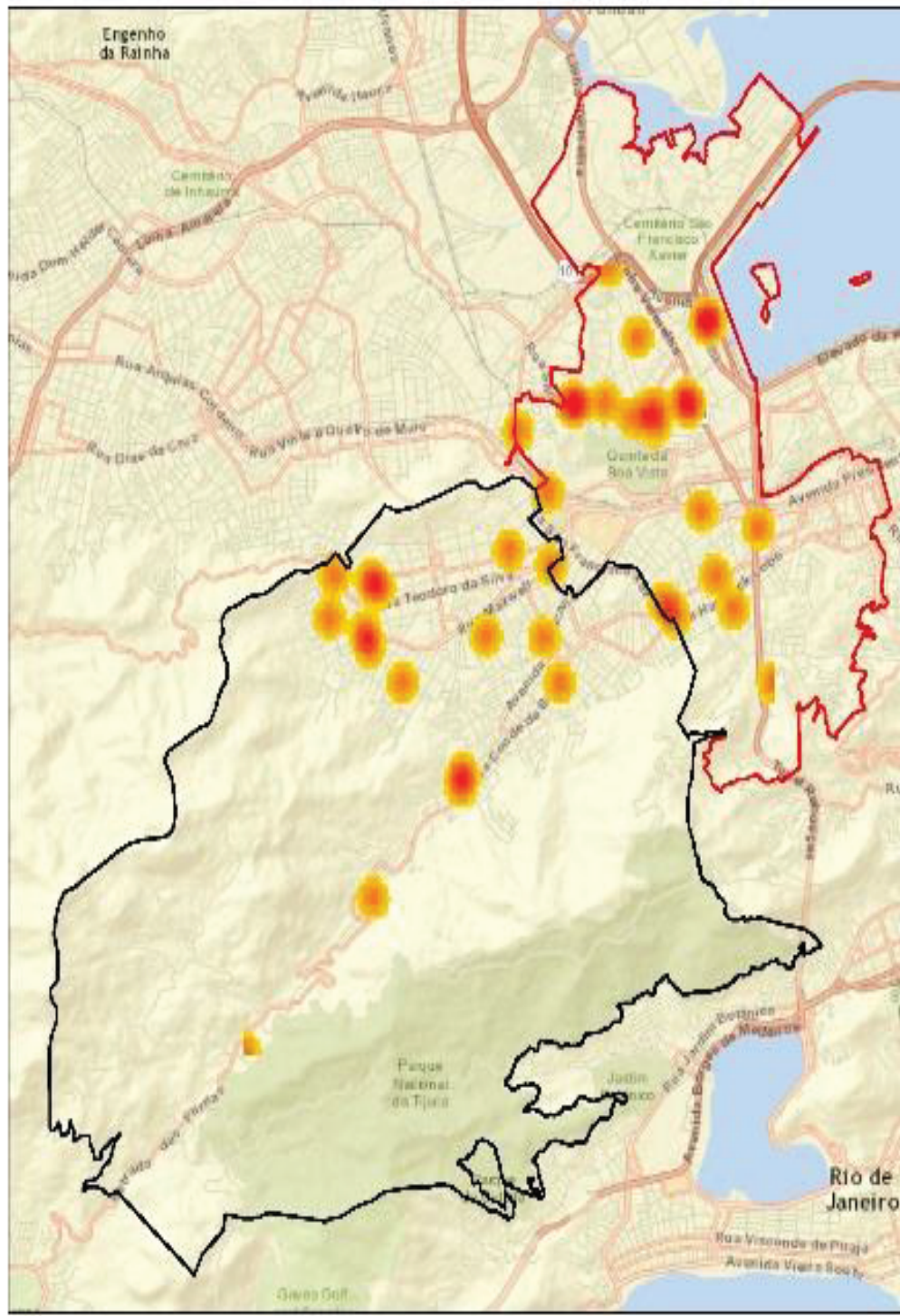

Escala: $1: 70.000$
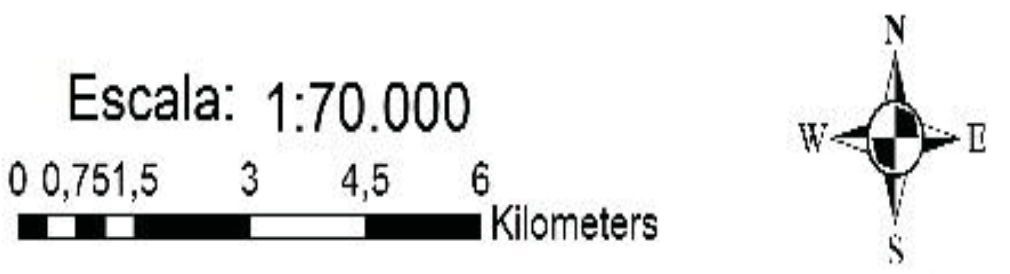

Fonte dos Dados:ISP/SSP-RJ

Figura 10 - Mapa de risco - Roubo de Veículos dados de fevereiro de 2013 


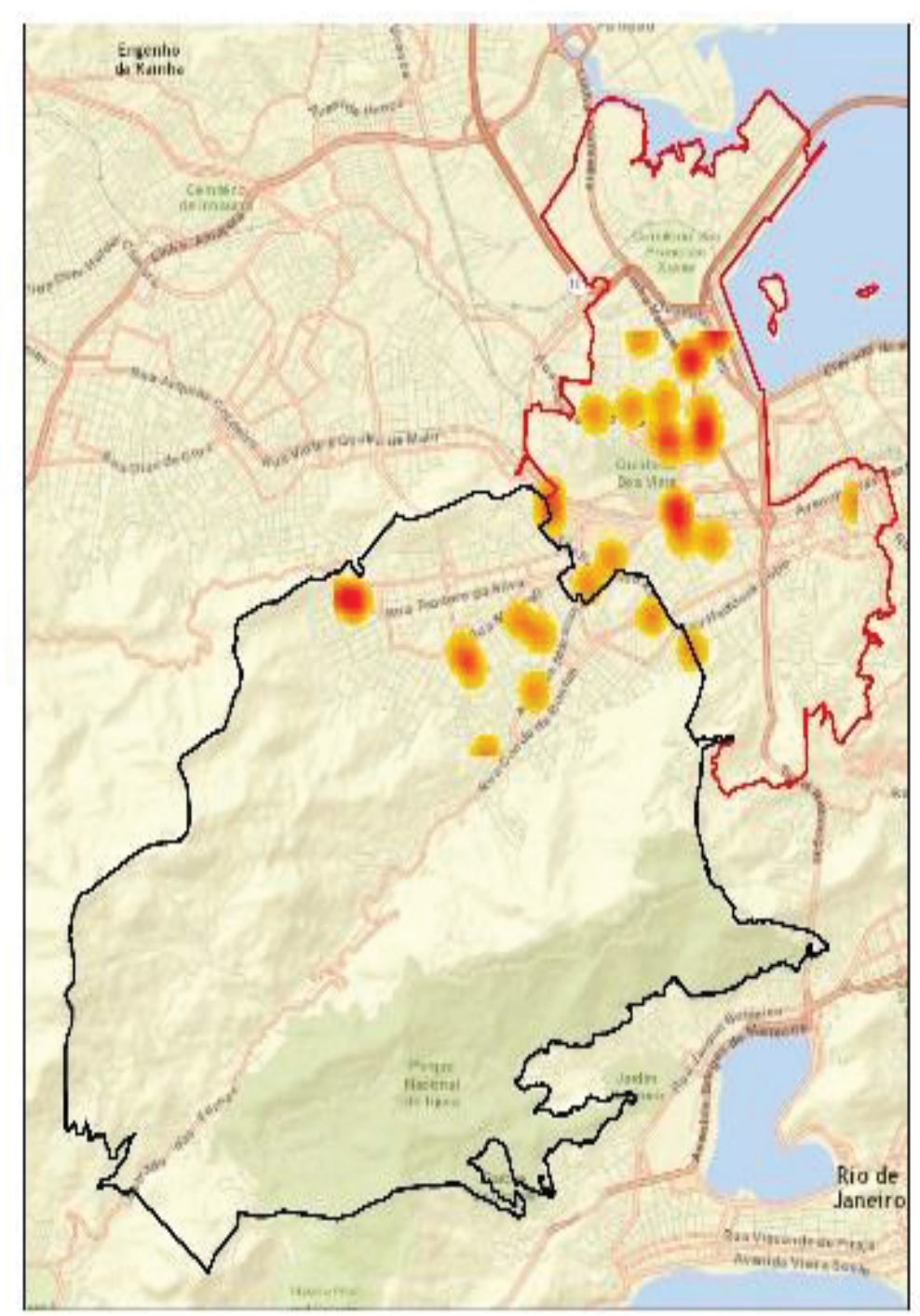

Escala: $1: 70.000$
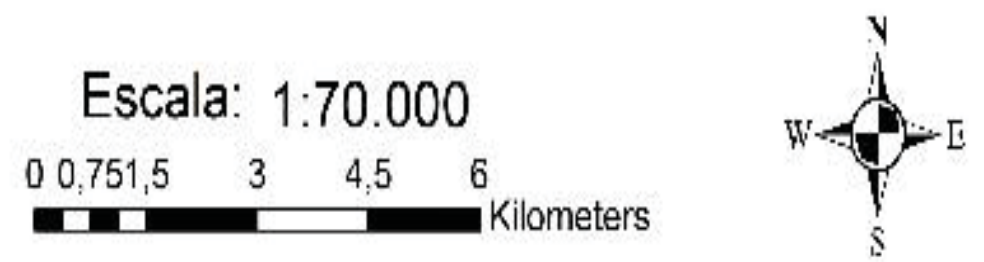

Fonte dos Dadoș:ISP/SSP-R.

Figura 11 - Mapa de risco - Roubo de Veículos dados de março de 2013 

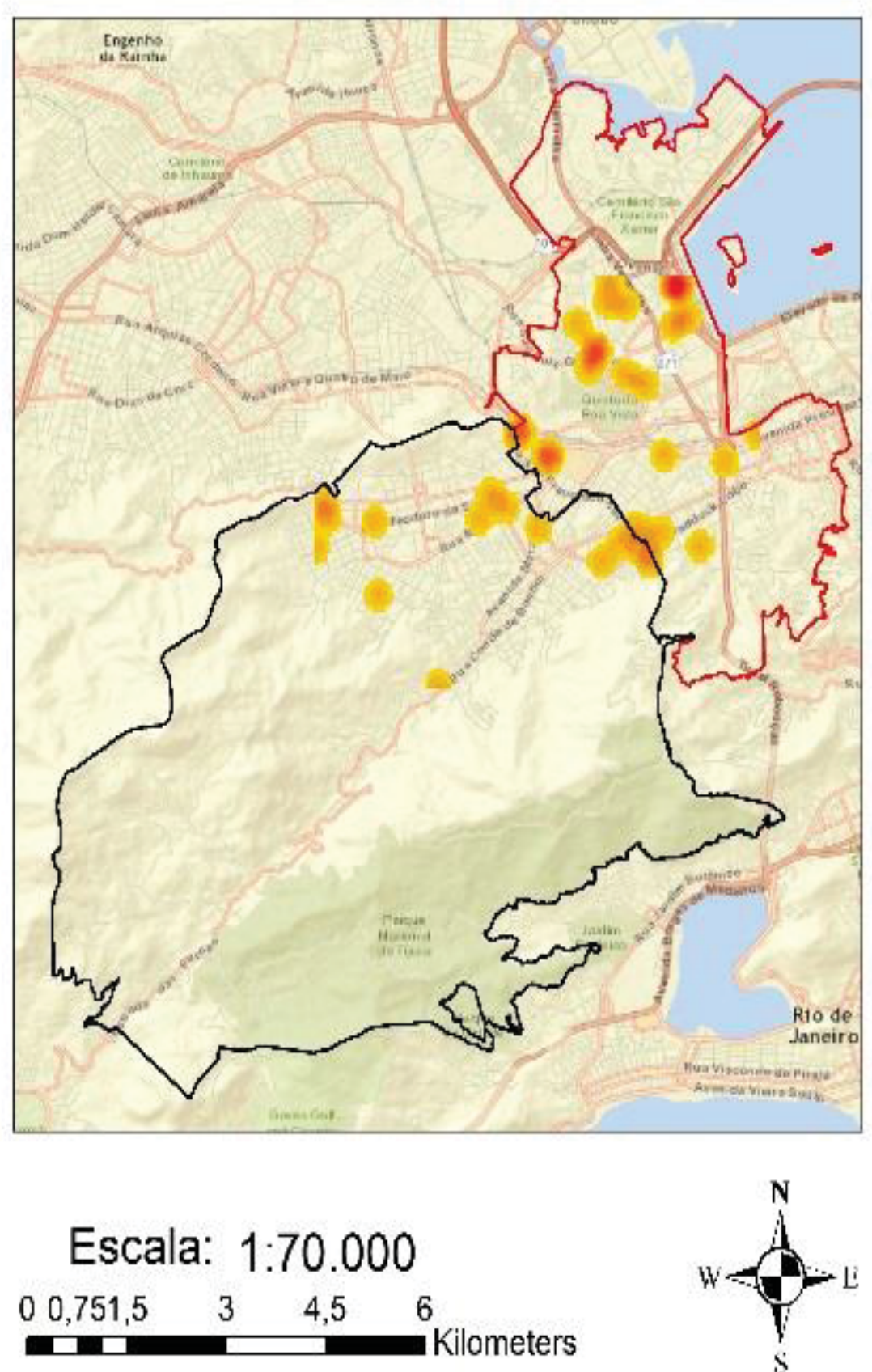

Fonte dos Dados:ISP/SSP-RJ

Figura 12 - Mapa de risco - Roubo de Veículos dados de abril de 2013 


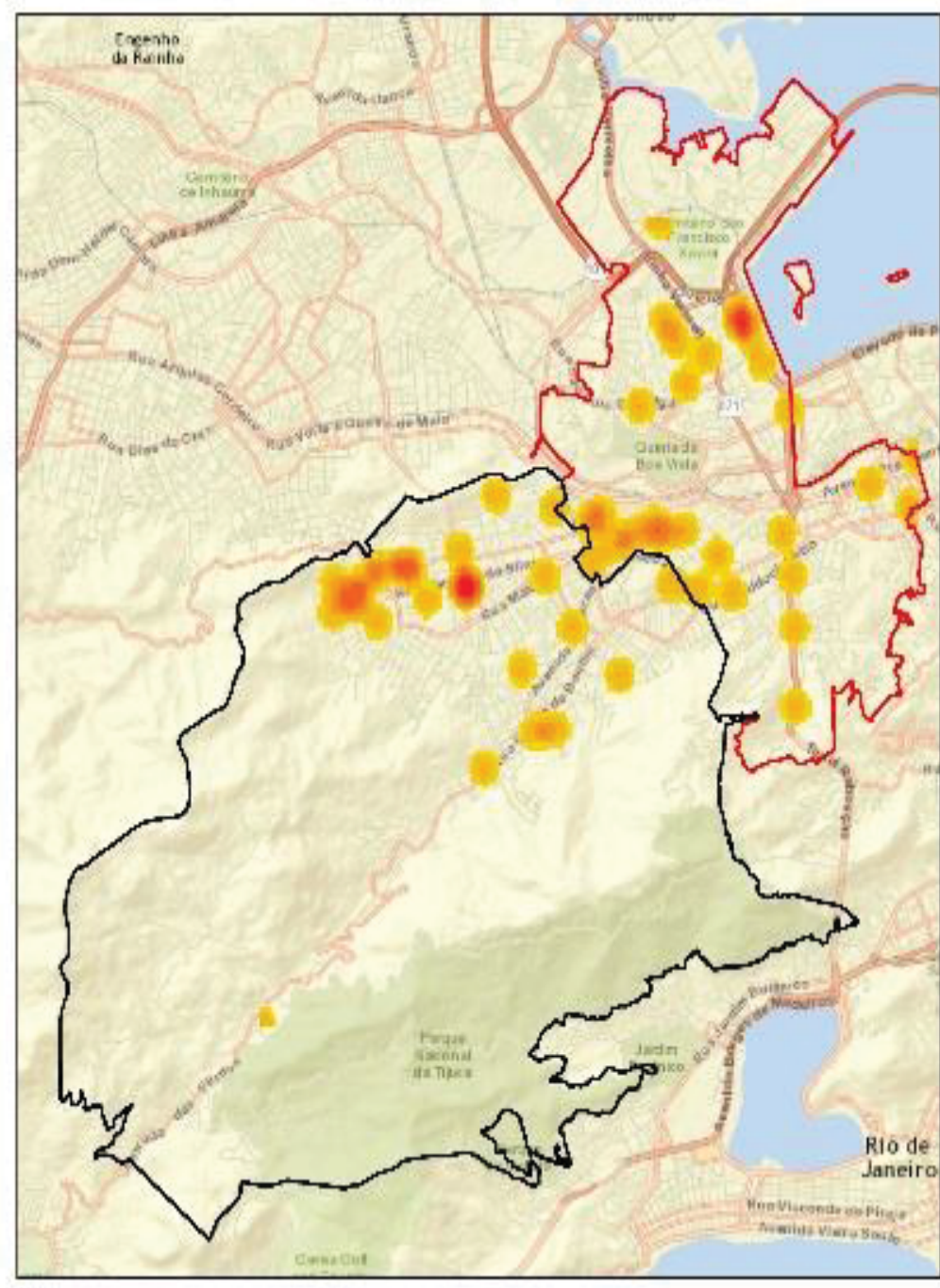

Escala: $1: 70.000$

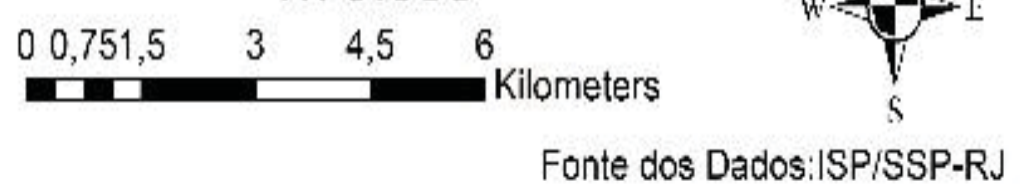

Figura 13 - Mapa de risco - Roubo de Veículos dados de maio de 2013 


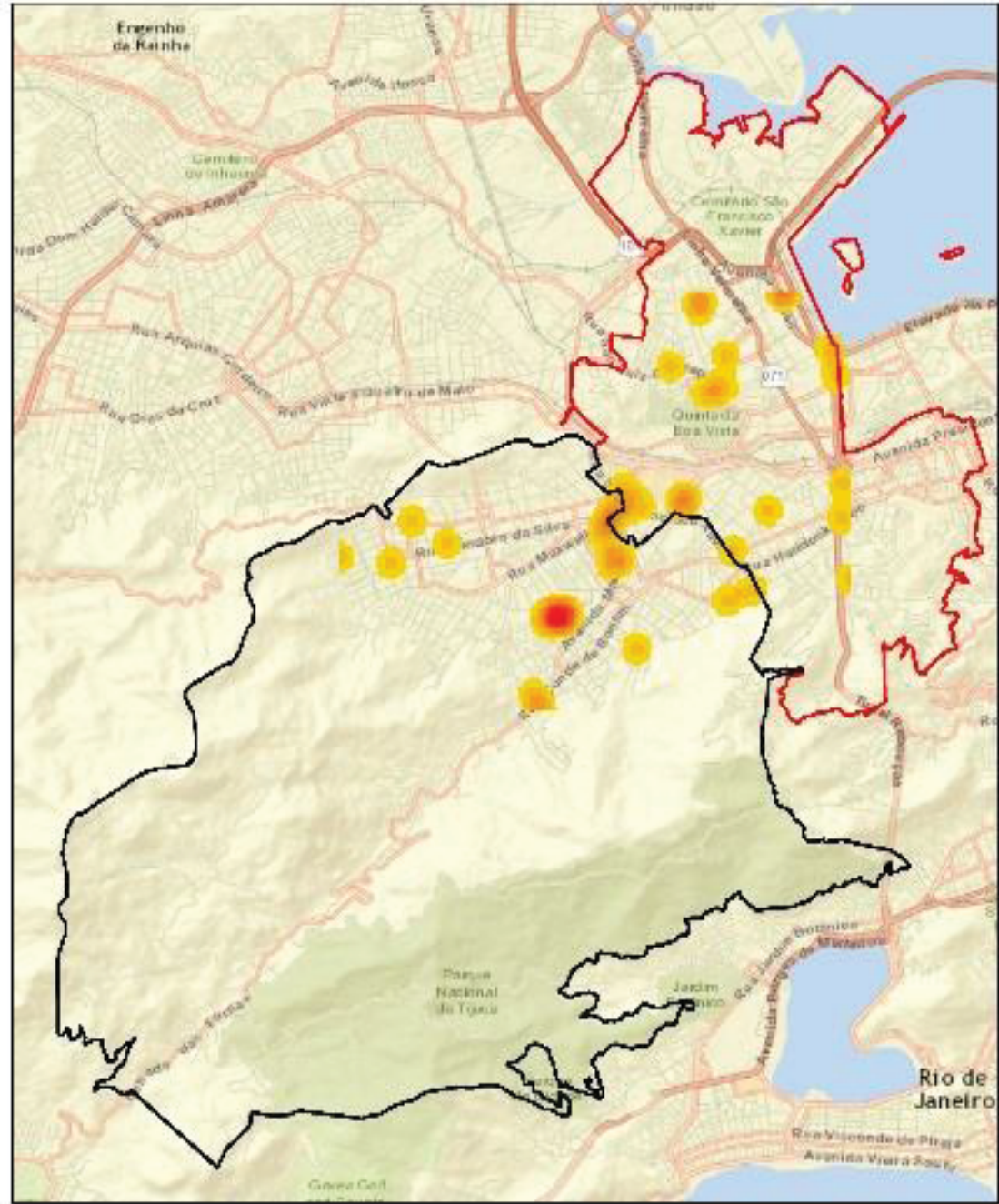

Escala: $1: 70.000$
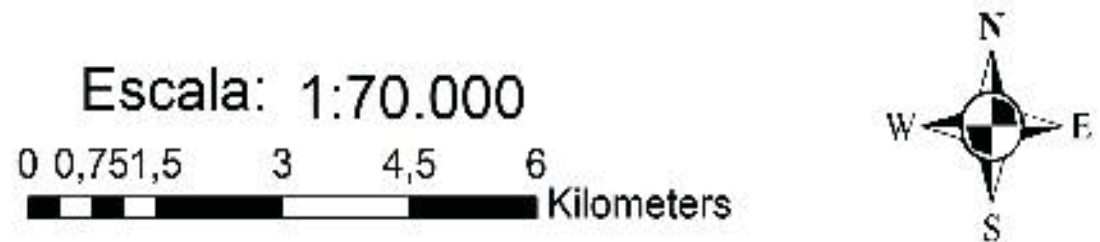

Fonte dos Dados:ISP/SSP-RJ

Figura 14 - Mapa de risco - Roubo de Veículos dados de junho de 2013 
Da simples visualização dos mapas acima, percebe-se que, para o planejamento tático das unidades policiais envolvidas, a utilização das ocorrências do mês anterior parece muita mais adequada do que analisar todas as ocorrências do ano. Primeiramente porque, devido ao número muito maior de ocorrências, é natural que haja uma maior poluição do produto anual quando comparado aos mapas mensais. Ademais, devido a maior proximidade no tempo das ocorrências analisadas, é intuitivo que seus dados sejam mais adequados ao planejamento de ações táticas.

A melhor adequação da análise mensal é também comprovada se observamos as elipses de desvio padrão mostradas anteriormente. Como já se disse, todas possuem pequeníssimas diferenças quando analisadas mês a mês, seja em relação a distribuição, tendência central e orientação geral, ocorrendo uma maior variação somente em relação a elipse construída a partir dos dados anuais.

Para se chegar a mesma conclusão, porém com o emprego de outra técnica, desta vez com o uso dos mapas de risco, propóe-se a seguinte metodologia: seleciona-se dois mapas de superfícies referentes a dois meses subsequentes, no caso concreto, março e abril. Posteriormente, com o software SIG empregado, o ArcGIS 10.2, efetuam-se as operaçóes a seguir: incialmente cria-se, através da ferramenta raster calculator, nova camada raster, cujas quadrículas terão como valor numérico a diferença entre os valores das quadrículas dos mapas de risco de março e abril (Operação= Mapa de Abril Mapa de Março). Posteriormente, tendo em vista que interessa o valor absoluto da quadrícula obtida com a operação anterior, representando a variação do risco nos meses analisados, não sendo relevante, para o presente estudo se houve aumento ou diminuição, efetuou-se a operação ABS, passando-se a trabalhar tão somente com números positivos. 
O resultado foi o mapa a seguir:

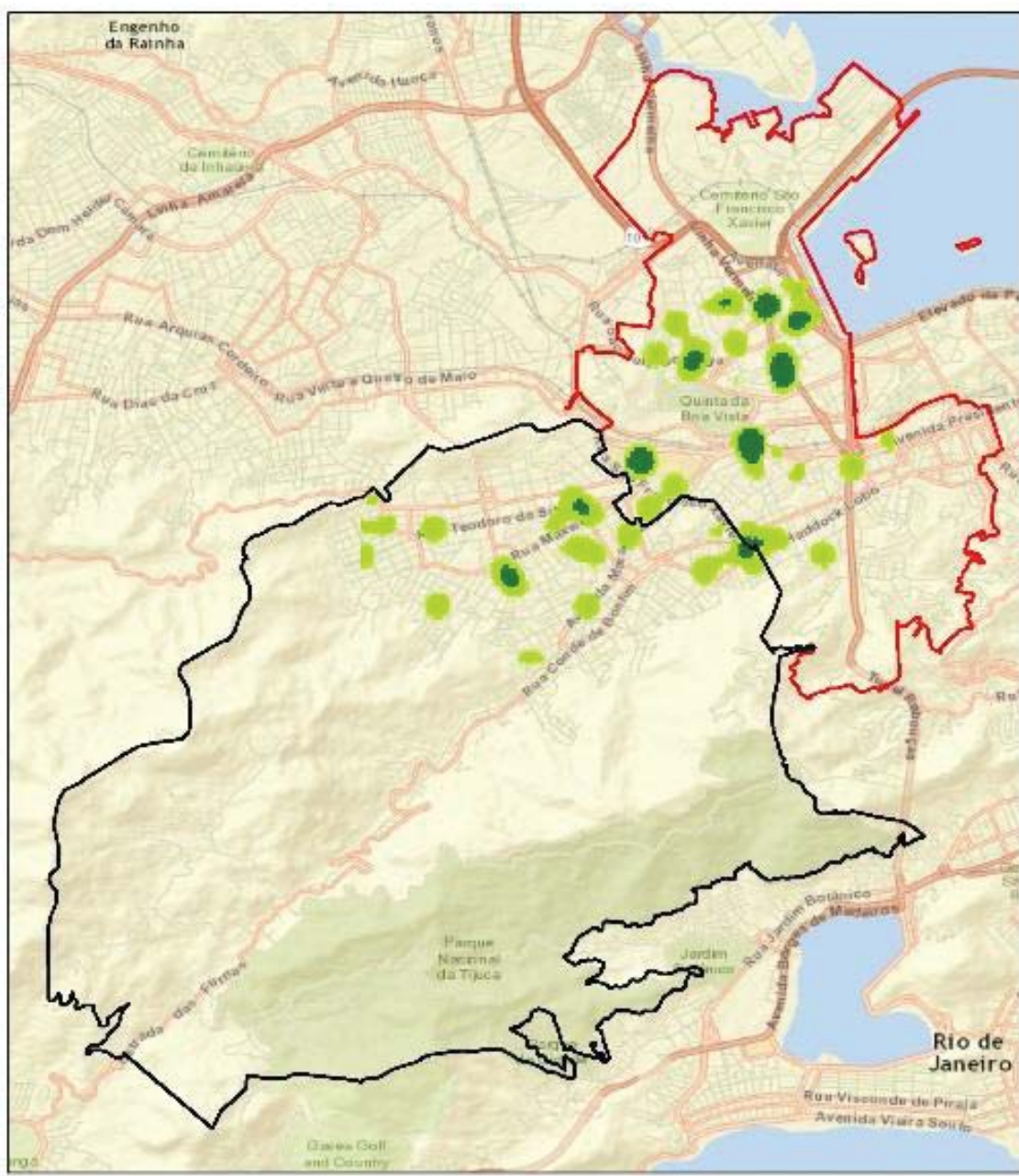

Escala: $1: 70.000$
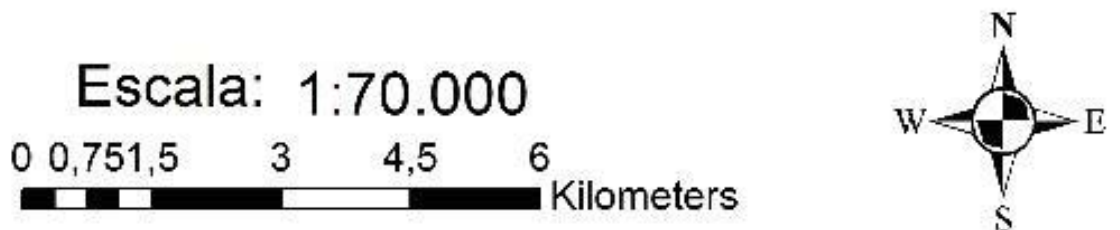

Fonte dos Dados:ISP/SSP-RJ

Figura 15 - Variação do Risco entre os meses de abril e março de 2013

Ao comparar-se o mapa acima obtido, percebe-se que poucos pontos, dentre toda a extensão da área estudada, tiveram variação numérica significativa entre os meses analisados. E ainda assim, ao compararmos a figura acima com os "hot spots" identificados nos meses de março e abril, verifica-se que a distância entre estes e os pontos de maior variação numérica é pequena, confirmando a grande concentração dos eventos estudados. Desta feita, 
pode-se concluir, seja pela maior proximidade no tempo, seja pela grande clusterização existente nos dados analisados, seja por serem produtos de mais fácil visualização, ou ainda, pela pequena variação nos mapas de superfícies entre meses subsequentes, que a análise mensal dos eventos mostra-se mais adequada para fins de planejamento tático.

\section{ANÁlise da MATriz de Hot SPots}

A matriz de hot spots foi proposta por Ratcliffe (2004) como uma forma de classificar, a partir de uma análise espaço temporal como a realizada no presente trabalho, os componentes de hot spots de crimes em categorias. São divididos em três categorias para a análise espacial e três para a temporal. Tais classes são descritas na chamada matriz de "hot spots" e tal divisão tem como objetivo auxiliar aos comandantes de polícia na tomada de decisões operacionais.

Para a elaboração de tal matriz, como proposto no trabalho acima mencionado, deve-se, inicialmente realizar análises espaciais e temporais dos crimes a serem estudados. Isso porque a forma de distribuição dos eventos criminosos analisados será utilizada como parâmetros para a classificação acima mencionada, de forma a criar uma tipologia para os hot spots de crimes.

Embora, teoricamente, existam infinitas possibilidades de distribuições tanto espaciais quanto temporais de hot spots criminais, Ratcliffe (ibidem) propõe a adoção de uma tipologia na qual as diversas formas de distribuição sejam reunidas em três categorias gerais referentes aos critérios temporais e mais três levando-se em consideração a análise espacial.

Assim, os hot spots seriam divididos, utilizando-se os critérios espaciais em: dispersa (dispersed), em cluster (clustered) e hot point. Ao se utilizar os parâmetros de tempos classificam-se em: difusa (difused), focada (focused) e aguda (acute). 
As figuras abaixo representam a forma da distribuição em cada um dos casos:

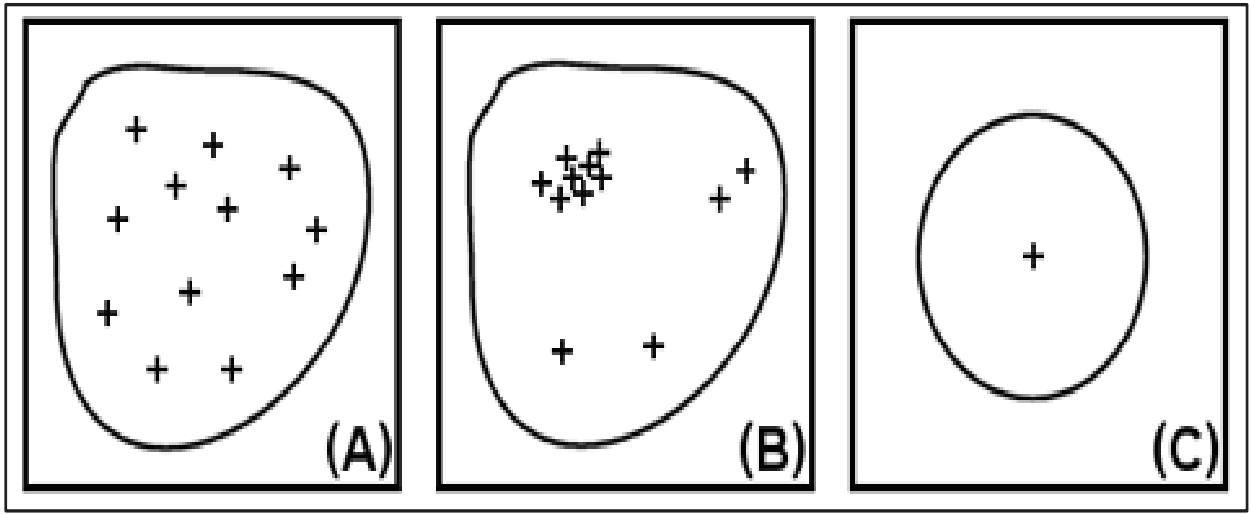

Figura 16 - Classificação de “hot spots” segundo critérios espaciais. (Fonte: Ratcliffe, 2004)

$\mathrm{Na}$ figura acima, pode-se perceber, na letra (A) uma distribuição do tipo dispersa, ou seja, não há uma concentração de eventos em uma determinada área. Já na (B), percebe-se que há uma grande concentração de eventos em uma determinada região, o que caracteriza a distribuição em cluster. $\mathrm{Na}$ (C), tem-se a distribuição hot point. Trata-se de uma forma de distribuição rara e que ocorre quando um único local atrai os eventos criminosos, como, por exemplo, um local de grande concentração, como shopping centers em áreas de baixa incidência criminal. Tais locais acabam registrando a totalidade dos eventos criminosos estudados.

Já na figura abaixo, tem-se a classificação segundo critérios temporais. Assim, a letra (A) indica uma distribuição temporal difusa, na qual os eventos se distribuem de forma mais ou menos uniforme ao longo do tempo. A letra (B) apresenta uma distribuição focada, ou seja, há concentração de eventos em determinados períodos do dia, embora ocorram em menor quantidade ao longo do dia inteiro. Já na letra (C) tem-se a distribuição aguda, qual seja, aquela em que as ocorrências se limitam a um determinado período.

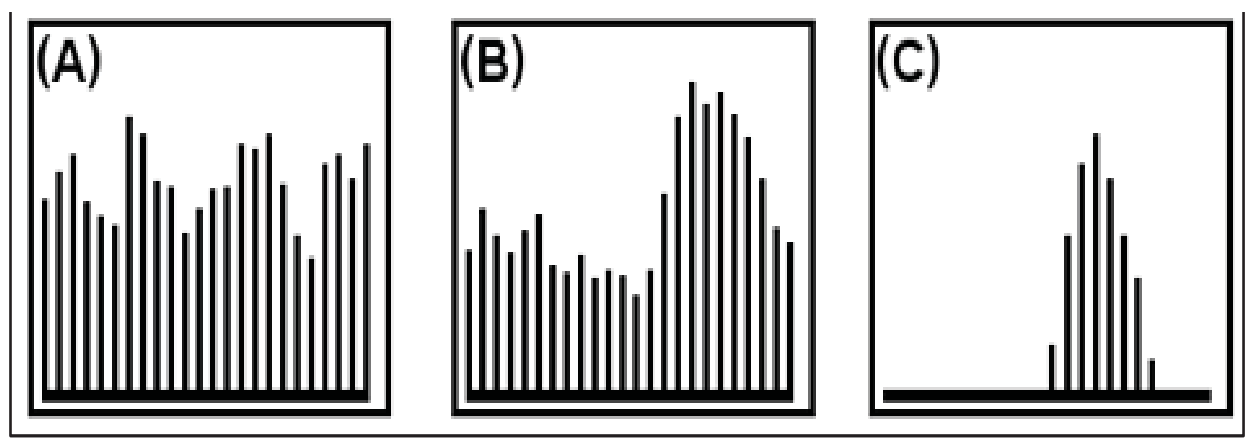

Figura 17 - Classificação de "hot spots" segundo critérios temporais. (Fonte: Ratcliffe, 2004) 
A adoção de tal tipologia tem como objetivo permitir, dentro do limitado tempo que possui o profissional de segurança pública, a tomada de decisões cientificamente baseadas, abandonando-se, ao menos em parte, o empirismo que atualmente fundamenta a maioria das decisóes na esfera policial.

Assim, com um sistema de classificação extremamente simples, é possível que, dentro do escasso tempo disponível, um gestor policial, tendo acesso a respostas padronizadas, fundamentadamente decididas e testadas para cada tipo de classificação, decida de forma mais eficiente.

A título de exemplo, segue abaixo matriz de hot spots apresentada por Ratcliffe (ibidem), na qual são sugeridas medidas adequadas para a redução da criminalidade, conforme a tipologia da distribuição dos eventos. Ressalte-se que tais medidas são apresentadas somente a título exemplificativo, já que, devido às variações as quais estão sujeitas as atividades policiais, não parece adequado a mera importação de sugestões alienígenas, o que não impede que cada força policial estabeleça uma matriz adequada a sua realidade, facilitando a aplicação no dia-a-dia dos princípios dos mais atuais modelos de gestão policial, caracterizados pela importância dada ao resultado da análise criminal, como, por exemplo, o policiamento orientado para a resolução de problemas ou o policiamento orientado pela inteligência. A tradução das medidas segue em nota de rodapé, na ordem das quadrículas da esquerda para a direita e de cima para baixo'.

1 Patrulhas veiculares ostensivas, mudanças de arquitetura e campanhas educativas. Testes de bafômetro aleatórios, patrulhas a pé, mudanças de arquitetura e campanhas de publicidade. Bloqueios de ruas, patrulhas descaracterizadas, testes de bafômetro aleatórios, segurança privada e circuito fechado de TV. Patrulhas ostensivas a pé e motorizadas, melhorias na iluminação e campanhas educativas. Patrulhas a pé e motorizadas, testes de bafômetro e segurança privada e melhorias na iluminação. Unidades de vigilância, patrulhas a pé descaracterizadas, circuito fechado de TV, vigilância nos pontos de entrada e saída. Patrulhas motorizadas descaracterizadas, segurança privada e melhorias na iluminação. Patrulhas de vigilância e descaracterizadas e Circuito Fechado de TV. Vigilância, equipes para prisões, circuito fechado de TV e unidades policiais descaracterizadas. (Tradução livre) 


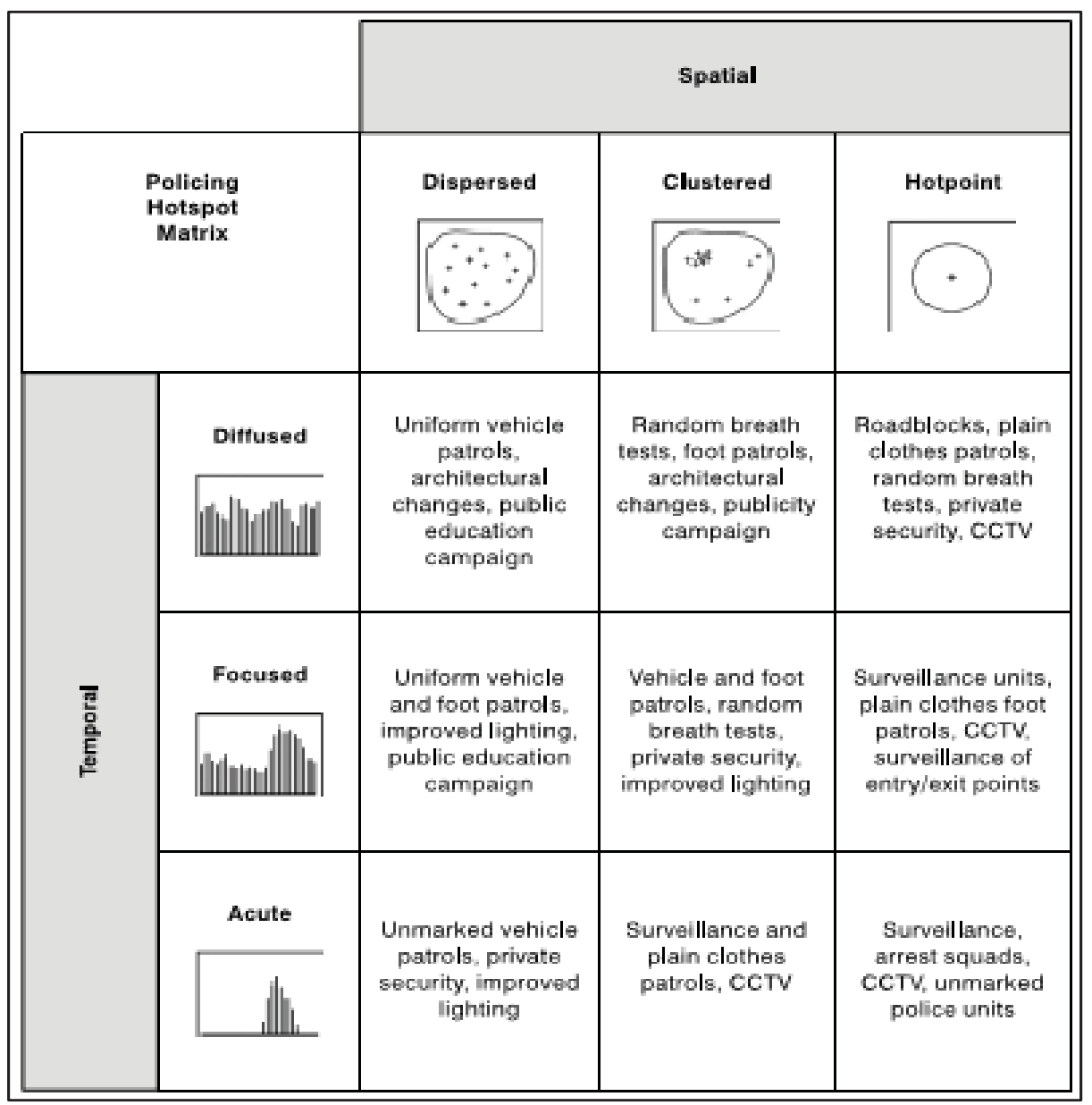

Figura 18 - Sugestão de matriz de "hot spots" Fonte: Rattcliffe, 2004

Analisando-se os dados referentes aos furtos de veículos ocorridos na região estudada no ano de 2013, percebe-se que se está diante de uma dispersão em cluster, quanto ao aspecto espacial, e focada, quanto ao aspecto temporal. Ressalte-se que esta classificação é baseada tão somente na análise da hora do dia em que ocorreu o roubo, em razão da maior relevância desse dado no planejamento operacional imediato.

Após identificar-se as classes da dispersão dos eventos aqui estudados, e empregando a matriz acima, ressaltando-se mais uma vez seu caráter meramente exemplificativo, percebe-se que dentre as medidas sugeridas para eventos desta classe as mais adequadas ao crime em estudo seriam o emprego de patrulhas motorizadas nas áreas e horários de pico, bem como melhorias na iluminação pública. De modo a facilitar a interpretação, no presente trabalho, realçou-se, com um quadrado vermelho, a célula correspondente à análise realizada. 
Destaque-se, as medidas a serem adotadas variam não somente com as características locais, mas também com o tipo de crime a ser enfrentado. Por isso, algumas medidas sugeridas na matriz acima não seriam adequadas ao problema enfrentado, como a realização de testes de bafômetro, o que não guarda qualquer relação com roubo de veículos.

\section{Conclusão}

Procurou-se, no presente trabalho, demonstrar como a análise criminal pode ser útil no planejamento das ações policiais. Com o advento de novo modelos de gestão de negócios para as polícias, tais como o policiamento orientado ao problema e o policiamento orientado pela inteligência, cada vez mais dependentes da inteligência e da análise criminal para subsidiar o processo decisório, em substituição ao modelo tradicional, baseado quase que unicamente em decisões empíricas. Desta forma, o papel do analista criminal é cada vez mais valorizado nas instituições policiais. Porém tais profissionais continuam tendo diversas limitações ao desenvolverem seu trabalho, em especial o pouco tempo disponível para cada análise.

Assim, espera-se que, com o emprego das técnicas de análise aqui apresentadas, aliadas à utilização da matriz de hot spots, consiga-se otimizar a utilização do tempo do analista criminal, tornando-o ainda mais fundamental ao bom desenvolvimento da atividade policial.

Wellington Clay Porcino Silva

Mestrando em CiênCia e Sistemas de Informações Geográficas na Universidade Nova de Lisboa. Possui Mestrado em Ciências Militares pela Escola de Aperfeiçoamento de Oficiais do Exército. Atualmente É Delegado do Departamento de Polícia Federal. Tem experiência na Área de Direito, com ênfase em Direito Penal,

Análise Criminal e Inteligência. 


\title{
Space-Time Analysis of Vehicle Theft OCCURRING DURING THE YEAR 2013 IN THE regions of the Integrated Areas of Public SAFETY 4 AND 6 IN RIO DE JANEIRO
}

\begin{abstract}
This paper analyzes the spatial and temporal characteristics of the vehicle thefts occurred in the regions of the integrated areas of public safety (PSIA) 4 (São Cristóvão and part of the Port Zone) and 6 (Grande Tijuca region) in the city of Rio de Janeiro in order to determine the spatial and temporal frequency of such events as a way to enable police managers a more efficient use of its human and material resources.
\end{abstract}

KEYwORDS: Criminal Analysis. Vehicle thefts. Rio de Janeiro. Police

\section{AnÁlisis Del Espacio-Tiempo de Robo de Vehículo OCurRidos durante el AÑo 2013 eN Regiones de Zonas de Seguridad Pública y INTEGRADO 4 Y 6 EN RIO DE JANEIRO}

\section{RESUMEN}

En este trabajo se tratará de examinar las características espaciales y temporales de los robos de vehículos ocurridos en las regiones de las áreas de seguridad pública integradas (PSIA) 4 (San Cristóbal y parte de la Zona Portuaria) y 6 (la región del Gran Tijuca) en la ciudad de Río de Janeiro con el fin de determinar la frecuencia espacial y temporal de los acontecimientos como una manera de permitir a los administradores de la policía un uso más eficiente de sus recursos humanos y materiales.

Palabras Clave: Análisis Criminal, robo de vehículos, Río de Janeiro, la policía. 


\section{REFER̂̂NCIAS}

CASELLA, George, e BERGER, Roger L (2010). Inferência estatística tradução da $2^{\text {a }}$ edição norte-americana. Centage Learning.

DANTAS, George Felipe, FERRO JÚNIOR, Celso Moreira (2008). A geografia na ciência e arte policial: aplicando uma ciência antiga na segurança pública moderna. In: "Conteudo Juridico", BrasiliaDF: 15 set. 2008. Disponivel em: <http://www.conteudojuridico. com.br/ ?artigos\&ver=2.21043\&seo $=1>$. Acesso em: 08 out. 2014.

PERRY, Walter L., MCINNIS, Brian, PRICE, Carter, SMITH Susan C., HOLLYWOOD, John S. (2013). Predictive Policing: The Role of Crime Forecasting in Law Enforcement Operations. Washington, DC: Rand Corporation.

RATCLIFFE, Jerry H (2004). "The Hotspot Matrix: A Framework for the Spatio-Temporal Targeting of Crime Reduction" in: Police Practice and Research, New York, v. 5, n. 1, pp. 05-23. . (2011). Intelligence-Led Policing. New York, NY:

Routledge.

SMITH, Susan C., BRUCE, Cristopher W. (2008). Crime Stat III:

Userbook. Washington, DC: The National Institute of Justice.

XUE, Yifei. BROWN, Donald (2003). “A Decision Model for Spatial Site Selection by Criminals: A Foundation for Law Enforcement Decision Support" in: IEEE Transactions on Systems, Man, and Cybernetics-Part C: Applications and Reviews, v. 33, n. 1, pp. 75-85. 